EESTI NSV TEADUSTE AKADEEMIA TOIMETISED. 20. KOIDE KEEMIA * GEOLOOGIA. 1971, NR. 2

ИЗВЕСТИЯ АКАДЕМИИ НАУК ЭСТОНСКОП ССР. ТОМ 20 ХимИЯ * ГЕОЛОГИЯ. 1971, № 2

УдК 543.544 .41 .662 .74

ЛИЛЬЯ ЛАХЕ, О. ЭИЗЕН

\title{
О СОДЕРЖАНИИ И СОСТАВЕ АРОМАТИЧЕСКИХ УГЛЕВОДОРОДОВ В ДИСТИЛЛЯТЕ КОКСОВАНИЯ ЭСТОНСКОГО СЛАНЦА
}

В настоящей работе представлен анализ дистиллята, выделяющегося при коксовании эстонской сланцевой смолы $\left[{ }^{1}\right]$, и содержащихся в нем ароматических углеводородов.

Методика анализа высококипящих ароматических углеводородов приводится ${ }^{2}\left[^{2,}{ }^{2}\right]$.

\section{Экспериментальная часть}

На сланцеперерабатываюшем комбинате им. В. И. Ленина в г. Кохтла-Ярве производится коксование смолы, состоящей из $70-75 \%$ генераторной и $30-25 \%$ камерной смол. Выделение дистиллята происходит в течение $16-17$. Проба дистиллята для исследования взята при нормальном режиме процесса.

Физические показатели исходного дистиллята коксования следующие: начало кипения $95^{\circ} \mathrm{C}$

$\begin{array}{cclr}\text { кипит до } & 130^{\circ} & 2,0 \% \\ ", & " & 200-280^{\circ} & 16,1 \% \\ " & " & 300-360^{\circ} & 59,5 \% \\ \text { кипит выше } & 360^{\circ} & 17,4 \%\end{array}$

Исходная смола перегонялась в вакууме (табл. 1). Как следует из табл. 1, содержание серы, определенной по методу Гроте, уменьшается с повышением температуры кипения фракций.

Фракции 1-7 дистиллята коксования были разделены жидкостноадсорбционной хроматографией на силикагеле на парафиновые, олефиновые и ароматические углеводороды и кислородсодержащие соединения. Данные группового состава приведены в табл. 2.

По групповому составу (см. табл. 2) видно, что содержание парафиновых и олефиновых углеводородов уменьшается с повышением температуры кипения фракций. Что касается фракций 6 и 7 , где наблюдается повышенное содержание этих групп, то тут, видимо, происходит ухудшение разделительной способности метода при анализе очень тяжелой смолы. Содержание ароматических углеводородов в смолах повышается с повышением температуры кипения фракций. Отклонения от этого общего правила обусловлены неполным разделением ароматики и кислородных соединений. Содержание кислородных соединений, остающихся в ароматическом концентрате, в тяжелой смоле повышается (до $67,7 \%$ в остатке дистилляции; рис. 1). 
таблица I

Данные вакуумной дистилляции исходной смолы

\begin{tabular}{|c|c|c|c|c|c|c|c|}
\hline $\begin{array}{c}\text { Фрак- } \\
\text { цня }\end{array}$ & $\begin{array}{l}\text { Пределы кипе- } \\
\text { ния фракции } \\
\text { при понижен- } \\
\text { ном давлении, } \\
{ }^{\circ} \mathrm{C}\end{array}$ & $\begin{array}{l}\text { Давле- } \\
\text { ние, } \\
\text { мм рт. ст. }\end{array}$ & $\begin{array}{c}\text { Пределы } \\
\text { кипения при } \\
\text { нормальном } \\
\text { давлении, } \\
{ }^{\circ} \mathrm{C}\end{array}$ & $\begin{array}{l}\text { Коли- } \\
\text { чество } \\
\text { фракций, } \\
\text { вес. \% }\end{array}$ & $\begin{array}{c}\text { Удель- } \\
\text { ный вес } \\
d_{4}^{20}\end{array}$ & $\begin{array}{c}\text { Показа- } \\
\text { тель пре- } \\
\text { ломления } \\
n_{D}^{20}\end{array}$ & $\begin{array}{c}\text { Содер- } \\
\text { жание } \\
\text { серы, } \\
\text { вес. \% }\end{array}$ \\
\hline $\begin{array}{l}1 \\
2 \\
3 \\
4 \\
5 \\
6 \\
7\end{array}$ & $\begin{array}{l}85-192 \\
192-233 \\
233-242 \\
168-197 \\
197-202 \\
202-220 \\
\text { Остаток } \\
\text { дистил- } \\
\text { ляшии }\end{array}$ & $\begin{array}{r}10 \\
10 \\
10 \\
2 \\
2 \\
2\end{array}$ & $\begin{array}{l}210-353 \\
353-407 \\
407-420 \\
375-420 \\
420-430 \\
430-456\end{array}$ & $\begin{array}{r}5,3 \\
28,4 \\
26,5 \\
15,0 \\
6,7 \\
2,3 \\
6,2\end{array}$ & $\begin{array}{c}0,914 \\
1,021 \\
1,031 \\
1,044 \\
- \\
-\end{array}$ & $\begin{array}{c}1,423 \\
1,478 \\
1,550 \\
1,561 \\
- \\
-\end{array}$ & $\begin{array}{l}1,31 \\
0,88 \\
0,84 \\
0,64 \\
0,59 \\
0,27 \\
0,49\end{array}$ \\
\hline
\end{tabular}

Потери

На рис. 1 изображена диаграмма состава ароматических концентратов, выделенных жидкостно-адсорбционной, газовой и тонкослойной хроматографией. Последним методом разделяются ароматические и остающиеся на стартовой линии кислородсодержащие соединения. При газохроматографическом анализе ароматические и кислородные соединения остаются неразделенными вследствие применения неполярной колонки.

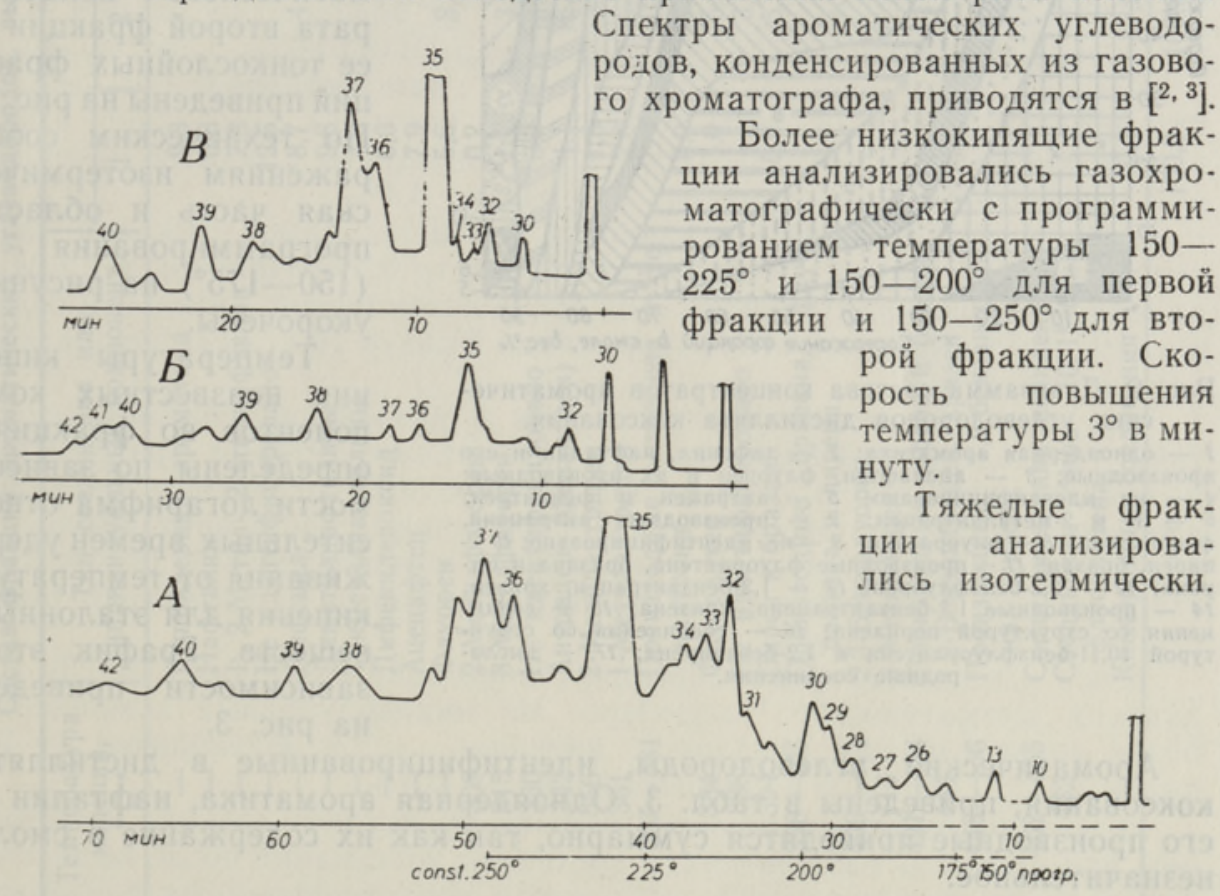

Рис. 1. Хроматограммы ароматических углеводородов второй фракции $(A)$ и ее тонкослойных фракций ( $E$ и $B)$. Анализ проведен с программированием температуры $150-250^{\circ} \mathrm{C}$ и изотермически: $\quad$ - $200^{\circ} \mathrm{C}, B-250^{\circ} \mathrm{C}$. Колонка длиной

$6 \mathrm{M} ; 5 \%$ апиезон $L$ на хромосорба; газ-носитель - гелий.

Названия компонентов, обозначенные цифрами, см. в табл. 3. 
Групповой состав дистиллята коксования

\begin{tabular}{|c|c|c|c|c|}
\hline \multirow[b]{2}{*}{ Фракция } & \multicolumn{4}{|c|}{ Состав, вес. $\%$} \\
\hline & Парафиновые & Олефиновые & Ароматическис & Кислородные \\
\hline 1 & 14,6 & 18,0 & 40,1 & 27,3 \\
\hline 2 & 5,5 & 8,1 & 46,3 & 40,1 \\
\hline 3 & 3.9 & 6,7 & 38,4 & 51,0 \\
\hline 4 & 3,6 & 0,2 & 39,1 & 57,1 \\
\hline 5 & 3,3 & 0,8 & 48,7 & 47,2 \\
\hline 6 & 5,8 & 1,0 & 45,4 & 47,8 \\
\hline 7 & 5,6 & 2.6 & 39,4 & 52,4 \\
\hline
\end{tabular}

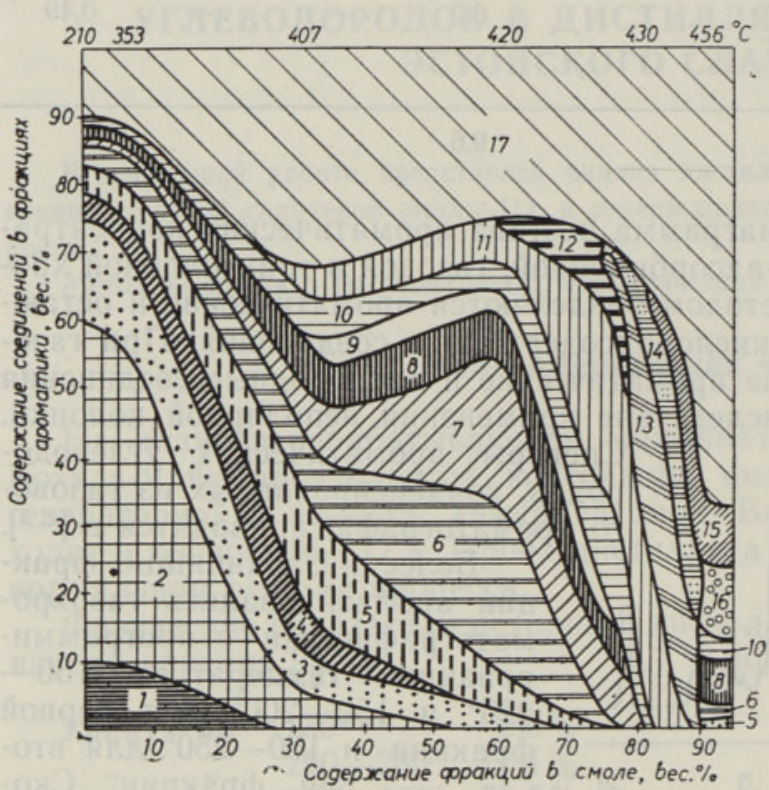

Рис. 2. Диаграмма состава концентратов ароматических углеводородов дистиллята коксования.

1 - одноядерная ароматика: 2 - дифеннл, нафталин и его пронзводные; 3 - аценафтен, флуорен и их производные: 4 - не идентифицировано; 5 - антрацен и фенантрен; 6 - 1- и 2-метилантрацен; 7 - пронзводные антрацена, фенантрена; 8 - флуорантен; 9 - не идентифицировано; $10-$ пирен, бразан; 11 - производные флуорантена, бразана и пи-

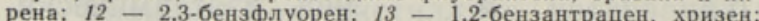
14 - производные 1,2-бензантрацена, хрнзена; 15 - соединения со структурой перилена; 16 - соединения со структурой 10,11-бензфлуорантена и 1,2-бензпирена; 17 - кислородные соединения.
Колонками служили: $10 \%$ Реоплекс 400 на хромосорбе $W(45-60$ меш) длиной $3 \mu$ (максимальная рабочая температура $220^{\circ}$ ) и высокотемпературная колонка $5 \%$ апиезон $L$ длиной $6 \mu$ на том же носителе.

Хроматограммы ароматического концентрата второй фракции и ее тонкослойных фракций приведены на рис. 2. По техническим сооб ражениям изотермическая часть и область программирования (150--175') на рисунке укорочены.

Температуры кипения неизвестных компонентов во фракциях определены по зависимости логарифма отно сительных времен удерживания от температур кипения для эталонных веществ. График этой зависимости приведен на рис. 3 .

Ароматические углеводороды, идентифицированные в дистилляте коксования, приведены в табл. 3. Одноядерная ароматика, нафталин и его производные приводятся суммарно, так как их содержание в смоле незначительное.

По составу арсматических углеводородов дистиллята коксования (рис. 1 и табл. 3) видно резкое уменьшение легких продуктов при переходе от первой фракции к следующим. Если в первой фракции производных нафталина и дифенила $49,6 \%$, то во второй фракции их содержание не превышает $4,6 \%$. Содержание антрацена и фенантрена с их производными составляет во второй фракции 33,0 и в третьей $-47,9 \%$. 


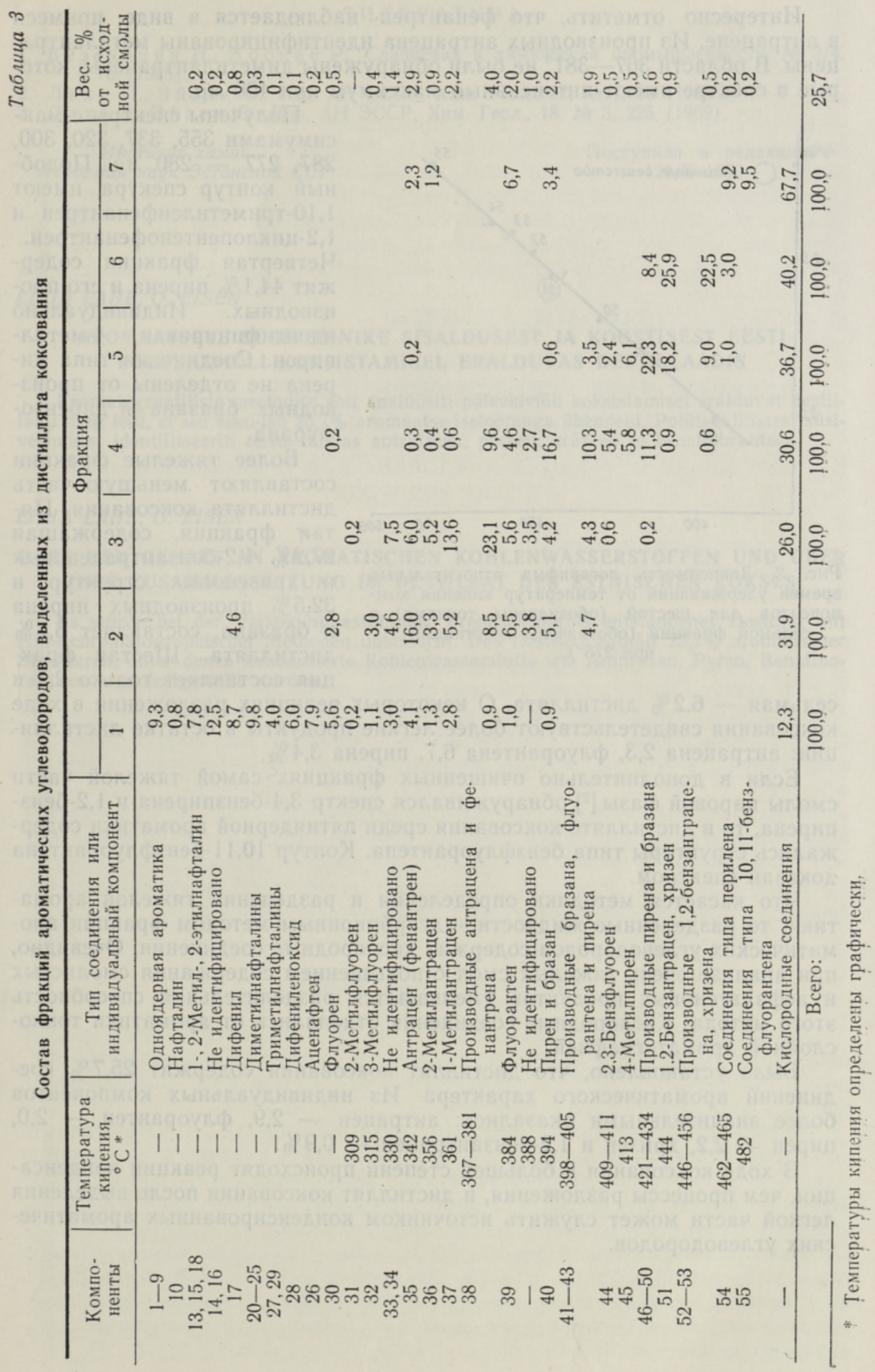


Интересно отметить, что фенантрен наблюдается в виде примеси в антрацене. Из производных антрацена идентифицированы метилантрацены. В области $367-381^{\circ}$ не были обнаружены диметйлантрацены, которые в спектре имеют интенсивный максимум при 400 м $\mu$.

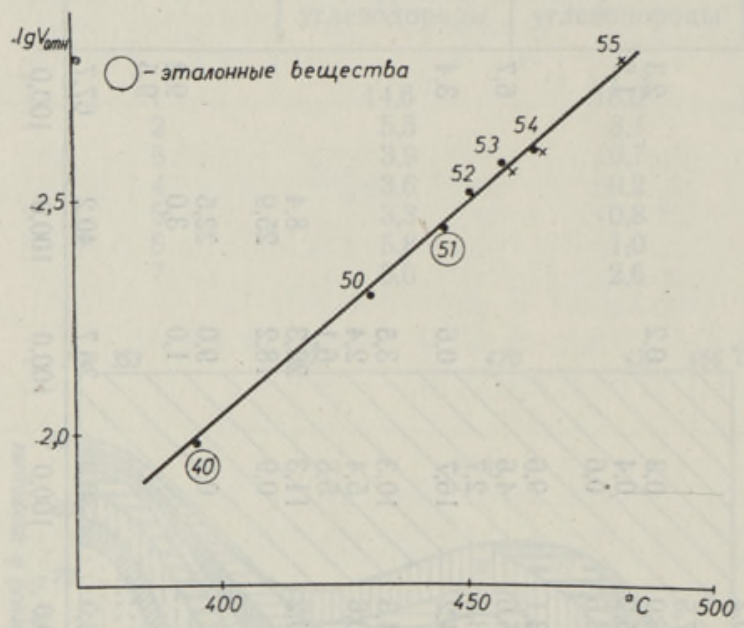

Рис. 3. Зависимость логарифма относительных времен удерживания от температур кипения компонентов для шестой (обозначены точками) и седьмой фракций (обозначены крестиками) при $275^{\circ} \mathrm{C}$.

Получены спектры с максимумами $355,337,320,300$, 287, 277 - 280 ми. Подобный контур спектра имеют 1,10-триметиленфенантрен и 1,2-циклопентенофенантрен. Четвертая фракция содержит $44,1 \%$ пирена и его производных. Индивидуально идентифицирован 4-метилпирен. Соединения типа пирена не отделены от производных бразана и дибензофурана.

Более тяжелые фракции составляют меньшую часть дистиллята коксования. Пятая фракция, содержащая $27,2 \%$ 1,2-бензантраценовых и хризеновых структур и $32,5 \%$ производных пирена и бразана, составляет $6,7 \%$ дистиллята. Шестая фрак ция составляет только 2,3 и

седьмая $-6,2 \%$ дистиллята. О некоторых реакциях разложения в ходе коксования свидетельствуют более легкие продукты в остатке дистилляции: антрацена 2,3 , флуорантена $6, \bar{\imath}$, пирена $3,4 \%$.

Если в дополнительно очищенных фракциях самой тяжелой части смолы паровой фазы $\left.{ }^{2}\right]$ обнаруживался спектр 3,4-бензпирена и 1,2-бензпирена, то в дистилляте коксования среди пятиядерной ароматики содержались структуры типа бензфлуорантена. Контур 10,11-бензфлуорантена доказан спектром.

Что касается методики определения и разделения тяжелой ароматики, то разделенные жидкостно-адсорбционным методом фракции ароматических углеводородов содержат кислородные соединения. Очевидно, при анализе очень тяжелых смол с повышением содержания смолистых и асфальтеновых продуктов уменьшается разделительная способность этого метода. Кислородные соединения отделялись от ароматики тонкослойной хроматографией.

Было установлено, что дистиллят коксования содержит 25,7\% соединений ароматического характера. Из индивидуальных компонентов более значительными оказались: антрацен - 2,9, флуорантен - 2,0, пирен - 2,2, хризен и 1,2-бензантрацен - 0,9\%.

В ходе коксования в большей степени происходят реакции конденсации, чем процессы разложения, и дистиллят коксования после выделения легкой части может служить источником конденсированных ароматических углеводородов. 


\title{
Л И ТЕ Р А Т Р А
}

1. Везеницин Н., Иоон ас Р., Сланцевая и химическая промышленность, № 3/4. $70(1965)$.

2. Л ахе Л., Э й з ен О., Изв. АН ЭССР, Хим. Геол., 17, № 1, 30 (1968).

3. Л ахе Л., Э й з е н О., Изв. АН ЭССР, Хим. Геол., 18, № 3, 225 (1969).

\author{
Институт химии \\ Академии наук Эстонской ССР \\ Поступила в редакцию \\ $21 / \mathrm{X} 1970$
}

\section{LILJA LAHE, O, EISEN}

\section{AROMAATSETE SUSIVESINIKE SISALDUSEST JA KOOSTISEST EESTI POLLVKIVIOLLI KOKSISTAMISEL ERALDUVAS DESTILLAADIS}

Kromatograafiliste meetodite abil analüüsiti põlevkiviōli koksistamisel eralduvat destillaati ning leiti, et see sisaldab $25,7 \%$ aromaatse iseloomuga ühendeid. Polütsüklilistest süsivesinikest identifitseeriti teiste hulgas antratseen, püreen, krüseen ja bensfluoranteen.

\section{LILJA LAHE, O. EISEN}

\section{OBER DEN GEHALT AN AROMATISCHEN KOHLENWASSERSTOFFEN UND UBER IHRE ZUSAMMENSETZUNG IM DESTILLAT DES ESTNISCHEN KOKSES}

Es wurde bei der Verkokung estnischen Brennschieferöls entstandenes Destillat mit Hilfe chromatographischer Methoden untersucht. Das Destillat enthält $25,7 \%$ aromatischer Strukturen, unter denen kondensierte Kohlenwasserstoffe wie Anthrazen, Pyren, Benzfluoranthen u. a. festgestellt wurden. 